\title{
Prototipe Sensor Rasa Portable Berbasis Campuran Lipid Dioctyl Phosphate Dan Trioctyl Methyl Ammonium Chloride Dengan Perbandingan Massa 9:1
}

\author{
Finta Amalinda \\ Universitas Muhammadiyah Palu, Jalan Hang Tuah No. 114, Palu \\ Email : Finta274866@gmail.com
}

\begin{abstract}
ABSTRAK. Telah dibuat prototipe sensor rasa portable berupa ion meter dua kanal dan satu membran selektif ion. Ion meter dua kanal dibuat sebagai awal pengembangan sistem sensor rasa atau electronic tongue (e-tongue) yang harusnya berupa ion meter multi-kanal. Ion meter dibuat dengan menggunakan IC op-amp LF412 sebagai amplifier dan mikrokontroller Atmega8535. Sementara itu, membran selektif ion dibuat dengan variasi campuran lipid dioctyl phosphate (DOP) dan triocthyl methyl ammonium chloride (TOMA). Dengan perbandingan massa masing-masing 9:1. Pada sensor rasa ini , lipid menetukan selektifitas membran terhadap ion-ion tertentu. Luaran dari sensor rasa (ion meter yang dilengkapi dengan membran selektif ion) berupa potensial listrik yang selanjutnya dibandingkan dengan potensial elektroda referensi. Selanjutnya, prototipe sensor rasa portable tersebut diuji kemampuan sensingnya terhadap lima macam larutan: glukosa, $\mathrm{KCl}$, kina, $\mathrm{HCl}$ dan MSG. Kelima larutan tersebut mewakili lima macam rasa dasar, yakni rasa manis diwakili oleh glukosa, rasa asin diwakili oleh $\mathrm{KCl}$, rasa pahit diwakili oleh kina, rasa asam diwakili oleh $\mathrm{HCl}$, dan umami diwakili oleh MSG. Setiap larutan sampel dibuat dengan pelarut $1 \mathrm{mM} \mathrm{KCl}$ dan divariasi menjadi tujuh macam konsentrasi. Sebagai hasilnya, sensor rasa dengan membran lipid campuran 9:1 menujukkan kecenderungan respon terhadap kation sampel, sehingga menghasilkan besar potensial yang mengalami peningkatan untuk setiap kenaikan konsentrasi.
\end{abstract}

Kata Kunci: $\quad$ sensor rasa, ion meter, membran selektif ion, lipid, diocthyl phosphate, triocthyl methyl ammonium chloride

\begin{abstract}
Portable taste sensor prototype has been fabricated as two channel ion meter and one types of ion selecting membrane. Two channel ion meter were made for pre development of the taste sensor system or as a electronic tongue wich acted as an multi channel ion meter.ion meter was made using IC op-amp LF412 as its amplifier and microcontroller Atmega8535. meanwhile types of the selecting membrane ion were made using variation: mix of lipid diocthyl phosphate (DOP) and triocthyl methyl ammonium chloride (TOMA) with mass ratio 9:1. On this sensor, lipid determines membrane selectivity to particular ions. Output from taste sensor is a electric potential and then it could be compared with electrode potential references. This portable taste sensor prototype is then tested is ability to sensing for 5 types of solution: glucose, $\mathrm{KCl}, \mathrm{HCl}$, quinine, and MSG. Those 5 types represent 5 basic taste: sweet by glucose, salty by $\mathrm{KCL}$, sour by $\mathrm{HCl}$, bitter by quinine, and umami by MSG. Every solution is made using $1 \mathrm{mM} \mathrm{KCl}$ solution and it is variated to be 7 types of concentration. As a result, taste sensor with lipid membrane mixture of 9:1 showed a tendency to respond to the cations sample, resulting potential which increased for every increase in concentration.
\end{abstract}

Keywords: taste sensor, ion meter, ion selecting membrane, lipid, diocthyl phosphate, methyl ammonium chloride.

\section{PENDAHULUAN}

Makanan merupakan sumber tenaga bagi manusia. Manusia menggunakan inderanya berupa lidah untuk mengetahui rasa suatu makanan. Rasa makanan terbagi atas lima macam rasa dasar, biasanya rasa manis diwakili oleh glukosa, rasa pahit diwakili oleh kina, rasa asin diwakili oleh $\mathrm{KCl}$, rasa asam diwakili oleh $\mathrm{HCl}$, dan rasa umami diwakili oleh MSG.

Selama ini pengukuran rasa dilakukan dengan metode analisis konvensional dan tester manusia. Metode analisis kimia konvensional misalnya biosensor dan kromatografi, sedangkan metode 
yang paling umum digunakan adalah tester manusia berupa lidah. Namun dalam metode-metode ini juga ditemukan beberapa kelemahan, diantaranya [4]:

- Dalam biosensor, terdapat kesulitan untuk menghasilkan sensor yang selektif terhadap jumlah substansi kimia tertentu.

- Alat kromatografi memiliki nilai ketepatan yang tinggi, namun biaya pengoperasiannya sangat mahal.

- Pengukuran rasa yang menggunakan panel uji manusia bersifat subjektif dalam menentukan standar mutu. Emosi dan kesehatan penguji akan berpengaruh pada suasana hati dan akan mempengaruhi hasil pengukuran. Untuk mengatasi kelemahan dari metode-metode diatas, maka diperlukan suatu metode baru yang mampu menganalisis suatu rasa. Metode tersebut dikenal sebagai sistem sensor rasa (electronic tongue).

Sistem sensor rasa terdiri atas sensor rasa sebagai elektroda kerja, elektroda $\mathrm{Ag} / \mathrm{AgCl}$ dengan single ceramic junction sebagai elektroda referensi dan keluaran dari kedua elektroda akan ditampilkan pada komputer, berupa pola sinyal yang digambarkan menggunakan metode principal component analysis (PCA). Untuk jenis yang sama, pola yang terbentuk akan mirip (secara visual maupun perhitungan kuantitatif).

Sensor rasa terdiri dari beberapa jenis membran lipid yang berfungsi untuk mengubah informasi rasa menjadi sinyal listrik. Lipid yang digunakan sebagai bahan membran yaitu: asam oleat (OA), oleyl amina (Oam) dan desil alkohol (DA), dioctyl phosphate (DOP), dan triocthyl methyl ammonium chloride (TOMA). Selain itu, digunakan pula membran lipid campuran DOP:TOMA dengan perbandingan 3:7, 5:5 dan 9:1 [7].

Keluaran dari sensor ini berupa intensitas rasa yakni pola potensial yang menggambarkan rasa itu sendiri. Apliksi dari sensor rasa sudah meluas di berbagai bidang. Dibidang farmasi, sensor rasa dimanfaatkan untuk mengetahui tingkat kepahitan obat dengan menambahkan zat pemanis dan mengoptimasi tingkat pemanis pada formula cair [10].

Di bidang industri, sensor rasa dimanfaatkan untuk memonitoring secara on-line kualitas susu mulai dari proses pengangkutan hingga proses pengemasan dan penyimpanan, hal ini untuk mengurangi resiko kerugian [9]. Di bidang biologi, sensor rasa berbasis voltametri digunakan untuk mengenali enam macam mikroorganisme berbeda [6].

\section{DASAR TEORI}

Manusia menggunakan lidah untuk merasakan suatu makanan atau minuman. Lidah tersususn atas reseptor rasa yang dinamakan perasa pada lidah (taste buds). Informasi suatu rasa zat diubah menjadi sinyal listrik yang selanjutnya ditransmisikan sepanjang serat syaraf ke otak, dimana suatu zat dikenali dan dirasakan (perceived). Manusia tidak dapat membedakan setiap zat kimia, tetapi dapat mengelompokkan rasa itu sendiri.

TABEL 1. Material lipid yang digunaan sebagai lari sensor [7].

\begin{tabular}{|c|l|}
\hline Channel sensor & \multicolumn{1}{c|}{ Jenis lipid } \\
\hline 1 & Decyl Alcohol (DA) \\
\hline 2 & Oleic Acid (OA) \\
\hline 3 & Diocthyl Phosphate (DOP) \\
\hline 4 & Oleyl Amine (Oam) \\
\hline 5 & Triocthyl Methyl Ammonium Chloride (TOMA) \\
\hline 6 & DOP : TOMA $=3: 7$ \\
\hline 7 & DOP : TOMA $=5: 5$ \\
\hline 8 & DOP : TOMA $=9: 1$ \\
\hline
\end{tabular}

Sistem sensor rasa yang dikenal dengan nama electronic tongue hadir sebagai terobosan baru untuk memperbaiki kelemahan manusia tersebut. Sekarang ini setidaknya ada dua sistem sensor 
rasa yang berkembang di dunia, yaitu sistem sensor rasa yang berdasarkan potensial dan voltametri [1]. Sensor rasa berdasarkan potensial perama kali dikembangkan oleh Toko dan grup risetnya [7]. Membran yang digunakan oleh Toko sebagai larik sensor terdiri atas delapan jenis lipid. Adapun kedelapan jenis lipid tersebut seperti yang tercantum pada tabel 1.

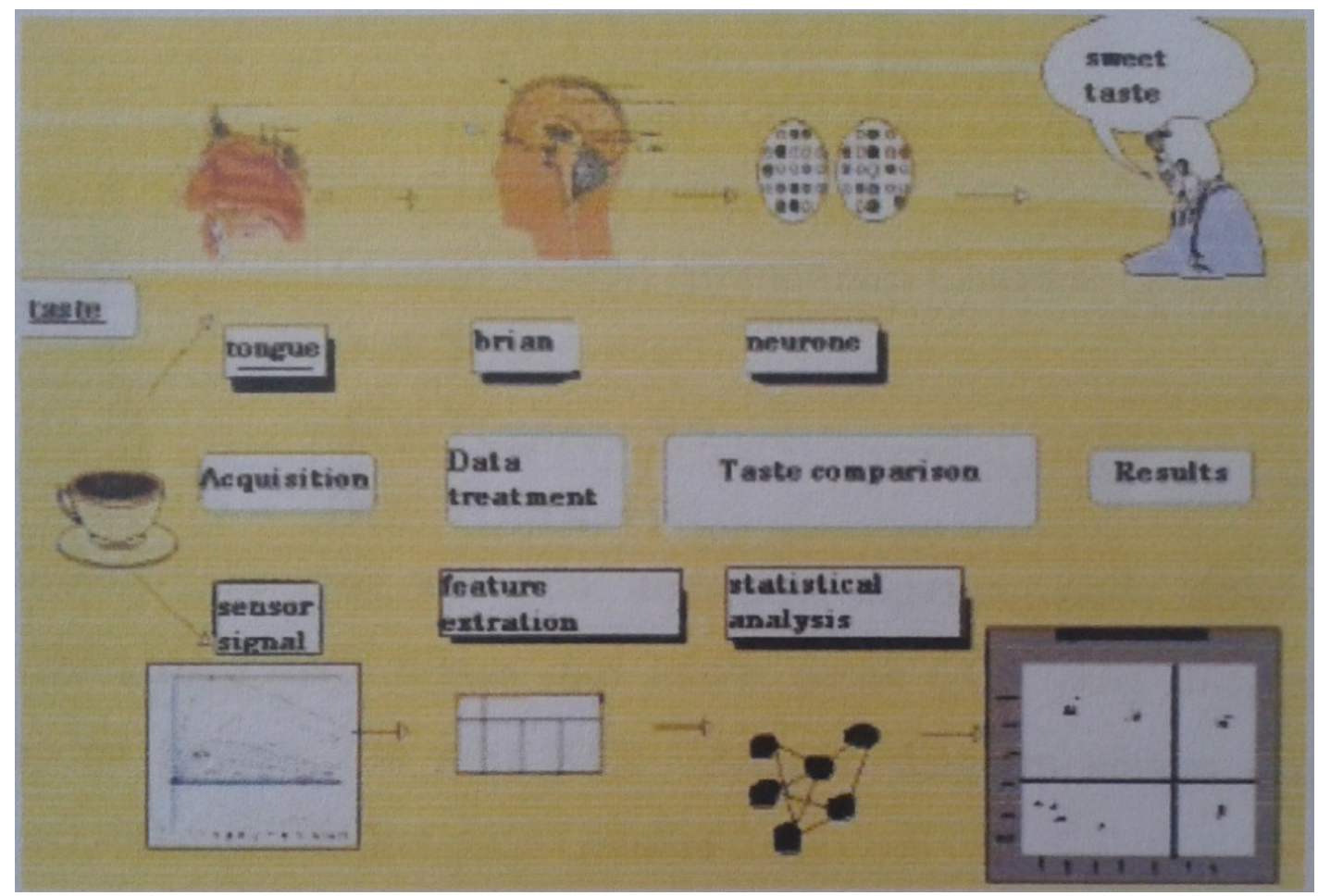

GAMBAR 1. Mekanisme pengenalan rasa pada manusia dan electronic tongue [5].

Membran lipid yang terbentuk kemudia dipasang pada elektroda kerja multikanal. Adapun diagram sistem sensor rasa berdasar potensial dapat dilihat pada gambar 2 .

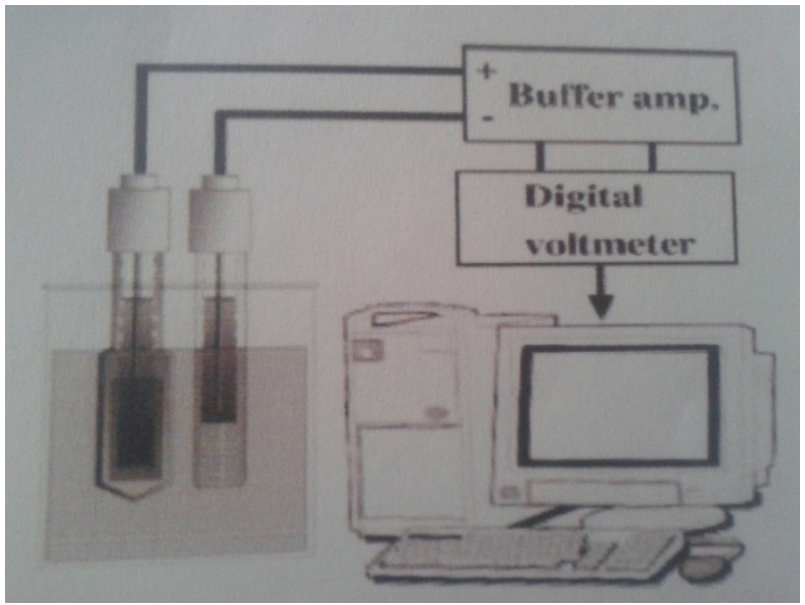

GAMBAR 2. Skema diagram sistem sensor rasa berdasar [2].

Jenis kedua dari electronic tongue adalah berdasar pada voltametri [8]. Sistem ini terdiri atas beberapa logam elektroda yang digunakan sebagai elektroda kerja, logam $\mathrm{Ag} / \mathrm{AgCl}$ sebagai elektroda referensi, dan elektroda stainless steel sebagai elektroda pencacah untuk sistem tiga elektroda standar. Voltametri memebrikan informasi tentang komposisi laeutan elektrolit dengan memplot karakteristik arus/tegangannya. 


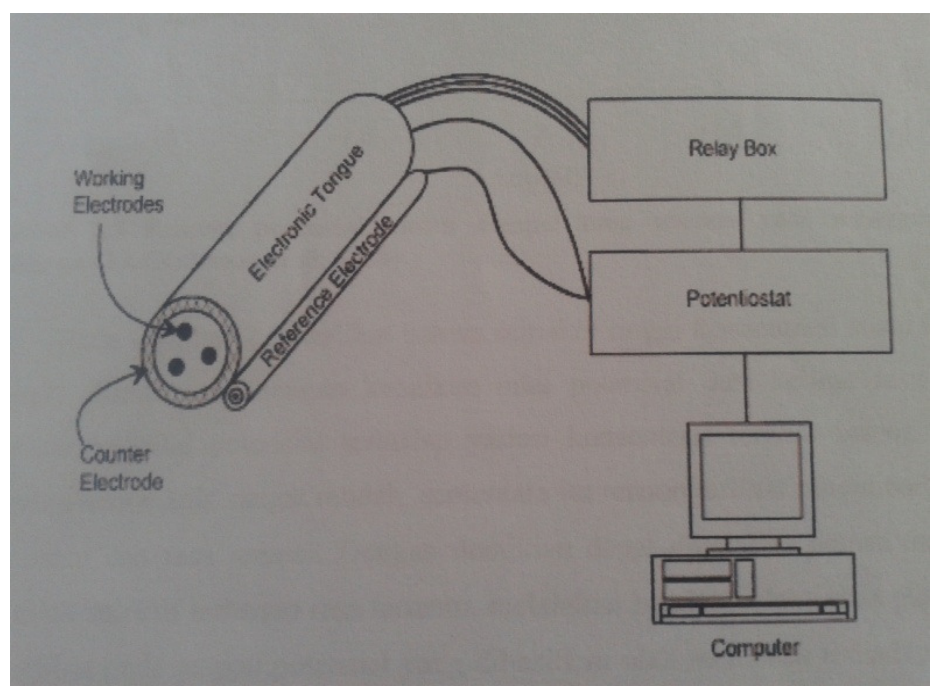

GAMBAR 3. Skema diagram sensor rasa berdasar voltametrik [3].

\section{METODE DAN BAHAN}

Pada penelitian ini terdiri dari beberapa tahap yang dapat ditunjukkan pada gambar 4 .

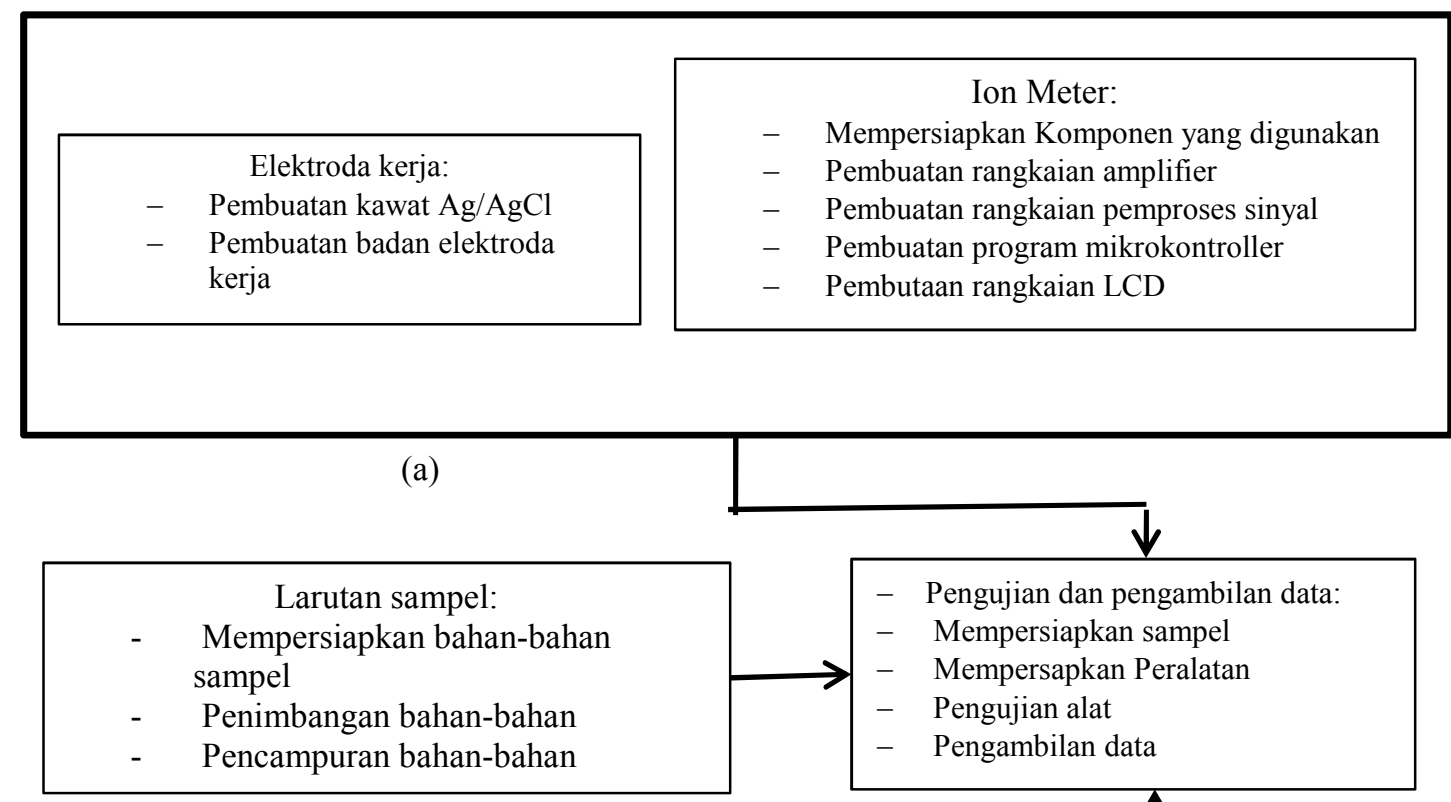

(b)

(d)

Membran:

- Mempersiapkan Bahan-bahan untuk membuat membran

- Penimbangan bahan-bahan

- Pencampuran bahan-bahan

- Penyimpanan membran dalam tabung membran

- Penguapan membran

- Pemotongan membran sesuai ukuran badan elektroda kerja

- Perendaman membran dalam larutan $1 \mathrm{mM} \mathrm{KCl}$

\section{(c)}

GAMBAR 4. Tahapan Penelitian (a) Pembuatan eletroda kerja dan ion meter, (b) pembuatan larutan sampel, (c) pembuatan membran, (d) pengujian dan pengambilan data 
Berdasarkan gambar diatas, tahapan penelitian terbagi menjadi beberapa tahap. Tahap pertama dalam penelitian ini adalah membuat elektroda kerja dan ion meter. Dalam pembuatan elektroda kerja yang dilakukan adalah pembuatan kawat $\mathrm{Ag} / \mathrm{AgCl}$. Kemudian dilanjutkan dengan pembuatan ion meter. Ion meter terdiri atas amplifier sebagai penguat tegangan dimana dalam penelitian ini menggunakan op-amp LF412, pemproses sinyal, dan LCD sebagai penampil besarnya nilai tegangan yang terukur. Tahap kedua dalam penelitian ini adalah pembuatan larutan sampel lima rasa dasar. Dimana untuk sampel lima rasa dasar menggunakan glukosa untuk mewakili rasa manis, $\mathrm{HCl}$ untuk mewakili rasa asam, $\mathrm{KCl}$ untuk mewakili rasa asin, kina untuk mewakili rasa pahit, dan umami untuk mewakili rasa gurih. Tahap ketiga dalam penelitian ini adalah tahap membuat membran. Adapun komposisi penyusun membran seperti yang ditunjukkan pada Tabel dibawah ini:

TABEL 2. komposisi penyusun membran

\begin{tabular}{|c|c|c|c|c|}
\hline \multicolumn{2}{|c|}{ Membran Lipid } & PVC & O-NPOE & \multirow{2}{*}{ THF } \\
\cline { 1 - 4 } Campuran & (\% massa) & (\% massa) & (\% massa) & \\
\hline DOP :TOMA $=9: 1$ & 8 & 28 & 64 & 3 \\
\hline
\end{tabular}

Tahapan terakhir yang dilakukan dalam penelitian ini adalah pengujian dan pengambilan data. Adapun langkah-langkah yang dilakukan dalam pengambilan data adalah sebagai berikut:

- Mula-mula elektroda referensi dan elektroda kerja dua kanal dimasukkan ke dalam larutan $1 \mathrm{mM} \mathrm{KCl}$ (larutan referensi) sambil diaduk dengan stirrer selama beberapa menit.

- Kedua elektroda diambil dan dikeringkan dengan tisu.

- Kedua elektroda dimasukkan kedalam sampel larutan misalnyaglukosa dengan konsentrasi $0,1 \mathrm{mM}$ sambil diaduk dengan stirrer selama \pm 4 menit.

- Mencatat potensial yang terbaca pada LCD

- Mengulang langkah penguian no 1 sampai no 4 untuk konsentrasi 0,3 mM, $1 \mathrm{mM}, 3 \mathrm{mM}$, $10 \mathrm{mM}, 30 \mathrm{mM}, 100 \mathrm{mM}$ untuk jenis rasa yang sama.

- Mengulag langkah pengujian no 1 sampai 5 untuk pengujian sampel yang lain $(\mathrm{HCl}, \mathrm{KCl}$, MSG, kina).

\section{HASIL DAN PEMBAHASAN}

Membran lipid yang digunakan dalam penelitian ini adalah membran lipid campuran DOP : TOMA dengan perbandingan massa masing-masing 9:1. Membran lipid dibuat dengan menggunakan campuran bahan kimia yaitu: lipid, PVC, THF, plasticizer dengan perbandingan tertentu dan ditempatkan pada tabung membran. Setelah itu tabung membran disimpan selama semalaman. Membran lipid yang terbentuk seperti yang tampak pada gambar 5.

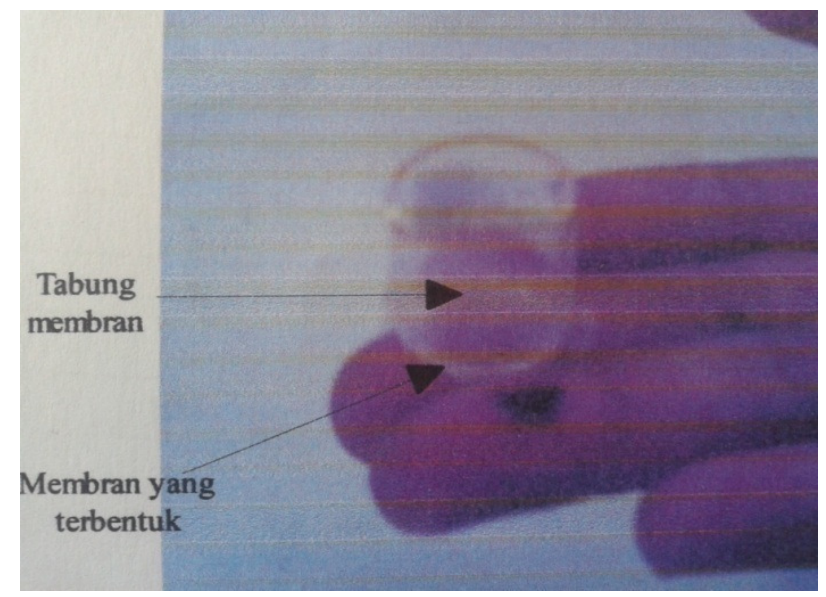

GAMBAR 5. Membran lipid yang terbentuk. 
Ion meter yang telah dibuat kemudian diuji menggunakan membran lipid campuran DOP:TOMA dengan perbandingan 9:1. Membran yang telah dibuat berfungsi untuk mengukur secara kuantitatif suatu rasa pada larutan sampel. Informasi rasa yang dikandung, diubah oleh lipid menjadi bentuk potensial listrik. Potensial listrik yang terbentuk akan diperkuat oleh amplifier yang ada dalam ion meter yang telah dibuat. Kemudian potensial listrik yang dihasilkan akan ditampilkan pada LCD. Adapun hasil hasil pengukuran dengan menggunakan membran lipid campuran DOP:TOMA dengan perbandingan 9:1 seperti pada tabel 3.

TABEL 3. Hasil pengukuran menggunaan membran lipid DOP:TOMA = 9:1

\begin{tabular}{|c|c|c|c|c|c|}
\hline \multirow{2}{*}{ Konsentrasi (mM) } & \multicolumn{5}{|c|}{ Potensial (mV) } \\
\cline { 2 - 6 } & HCl & Glukosa & KCl & Kina & MSG \\
\hline 0,1 & & & 167 & 19 & 13 \\
\hline 0,3 & 21 & & 168 & 28 & 14 \\
\hline 1 & 25 & & 169 & 44 & 18 \\
\hline 3 & 32 & -5 & 170 & 54 & 21 \\
\hline 10 & 41 & 6 & 171 & 56 & 24 \\
\hline 30 & 65 & 19 & 178 & 57 & 27 \\
\hline 100 & 80 & 21 & 190 & 62 & 30 \\
\hline
\end{tabular}

Profil respon membran lipid campuran DOP:TOMA = 9:1 untuk kelima sampel rasa dasar yang terukur dapat dengan jelas terlihat pada gambar 6.

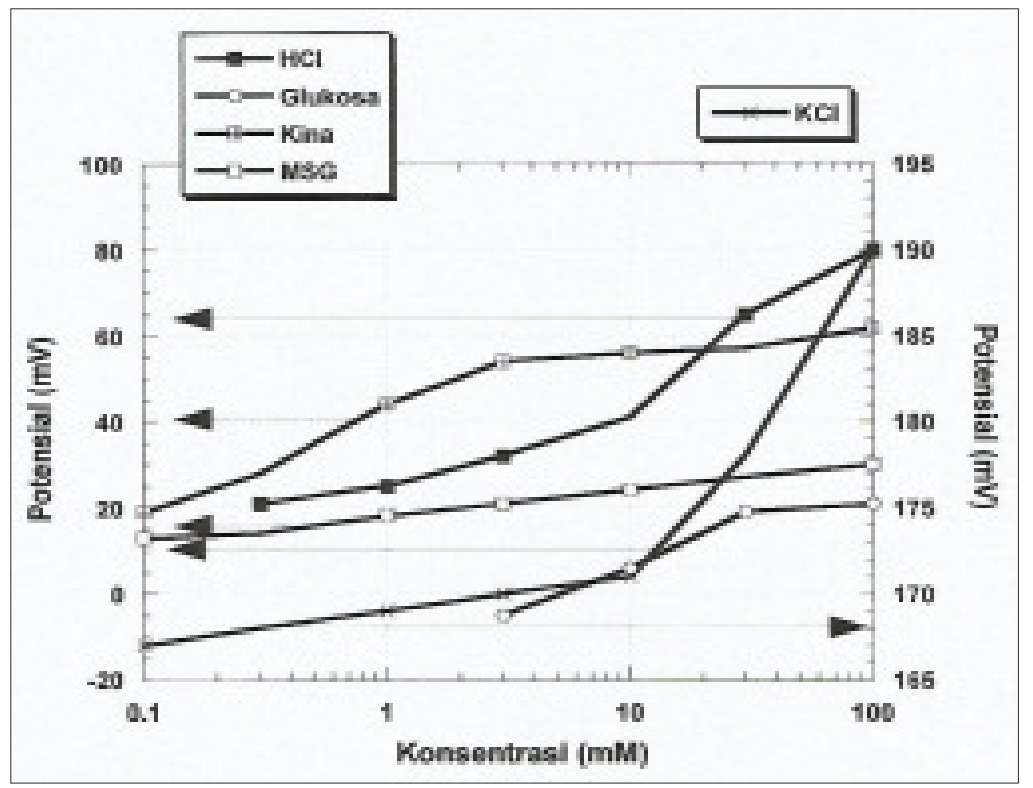

GAMBAR 6. Profil respon membran DOP : TOMA = 9:1 terhadap kelima rasa dasar.

Berdasarkan gambar 6, bahwa semakin tinggi konsentrasi suatu larutan sampel, maka besar potensial yang dihasilkan oleh membran lipid campuran DOP:TOMA $=9: 1$ untuk setiap rasa akan semakin meningkat. Hal ini dikarenakan membran lipid DOP merupakan membran yang bermuatan negatif oleh karenanya bersifat kationik, sedangkan membran lipid TOMA merupakan membran lipid yang bermuatan positif oleh karenanya bersifat anion ${ }^{[7]}$. Campuran kedua membran lipid dengan perbandingan DOP:TOMA $=9: 1$ menandakan bahwa membran lipid ini ebih bersifat kation atau kebanyakan merespon ion positif dikarenakan unsur lipid DOP lebih besar dibanding lipid TOMA. Hal inilah yang menyebabkan pola potensial untuk kelima rasa meningkat.

\section{KESIMPULAN}

Berdasarkan hasil penelitian, maka dapat diambil beberapa kesimpulan bahwa telah dibuat prototipe sensor rasa berupa ion meter dua kanal. Telah dibuat membran lipid campuran 
DOP:TOMA dengan perbandingan massa masing-masing 9:1. Membran lipid ini telah diujikan pada larutan sampel penghasil lima rasa dasar dimana setiap rasa terbagi menjadi tujuh variasi konsentrasi. Membran lipid dengan perbandingan DOP:TOMA $=9: 1$ didominasi oleh lipid DOP, oleh karenanya membran lipid ini respon terhadap kation sampel.

$$
2(\mathrm{RO})_{2} \mathrm{PO}_{2} \mathrm{H}_{(\text {membran })}+\mathrm{M}^{+}{ }_{(\mathrm{aq})} \Leftrightarrow\left(\mathrm{R}_{2} \mathrm{O}_{2} \mathrm{PO}_{2}\right)_{2}-\mathrm{M}^{+}{ }_{(\text {membran })}+\mathrm{H}^{+}{ }_{(\mathrm{aq})}
$$

Ketika diujikan pada sampel penghasil lima rasa dasar, membran lipid ini menghasilkan besar potensial yang mengalami kenaikan untuk setiap kenaikan konsentrasi.

\section{REFERENSI}

[1] Deng, Shao-ping., Tian, Shi-yi., and Chen, Zhong-Xiu., 2008, Multifrequency large amplitude pulse voltammetry: a novel electrochemical method for electronic tongue, Sensor and Actuators B 123, 1049-1056.

[2] Habara, M., Toko, K., and Ikezaki, H., 2003, Study Of sweet taste evaluation using taste sensor with lipid/polymer membranes, Biosensors and Bioelectronics, 1559-1563.

[3] Ivarsson, P., Hojer, N., Holmin, S., Krantz-Rulcker, C., and Winguist, F., 2001, Discrimination of tea by means of a voltammetric electronic tongue and different applied waveforms, Sensor and Actuator B, 449-454.

[4] Kaltsum U., Triyana, K., dan Siswanta, D., 2009, Fabrication and Characterization of Membrane Based on Taste Sensor to Classify Five Types of Basic Taste, Proc, ISSTEC 2009, 301.

[5] Sharma, P.K., Chaudhari, P.D., Chaudhari, S.P., Chaudhari, A.P., Barhate, N.S., and Mistry, C. J., 2006, Electronic Tongue: A Review, Pharmaceutical Reviews, Vol. 4, issue 3 .

[6] Soderstrom, C., Winguist, F., and Krantz-Rulcker, C., 2003, Recognition of Six Microbial Species with an Electronic Tongue, Sens. Actuators B (Chem.) B89 (3), 248-255.

[7] Toko , K., Imamura, T., Yanagizawa, S., and Kume, T., 1996, Monitoring of Fermentation Process of Miso (soybean paste) using multichannel taste sensor, Sensor and Actuators B 37, 179-185.

[8] Winguist, F., Wide, P., and Lundstorm, I., 1997. An electronic tongue based on voltametry, Anal. Chim, Acta 375, 21-31.

[9] Winguist, F., Bjorklund, R., krantz-R"ulcker, C., Lundstr”oma, I., Stergren, K., and Skoglund, T., 2005, An Electronic Tongue in the Dairy Industry, Sensors and Actuators B 111-112, 299-304.

[10] Zheng, J and Melissa P., 2006, Taste Masking Analysis in Pharmaceutical Formulation Development Using an Electronic Tongue, International Journal of Pharmaceutics, 310 , 118-124. 